\title{
Nanoconjugates Based on Cisplatin and Single-Walled Carbon Nanotubes for Therapy of Triple Negative Breast Cancer ${ }^{\dagger}$
}

\author{
Madalina Andreea Badea 1,*, Mihaela Balas ${ }^{1}$, Florentina Gina Cojocaru ${ }^{2}$, Daniela Ionita ${ }^{3}$ and Anca Dinischiotu 1 \\ 1 Department of Biochemistry and Molecular Biology, Faculty of Biology, University of Bucharest, \\ 91-95 Splaiul Independentei, R-050095 Bucharest, Romania; mihaela.balas@bio.unibuc.ro (M.B.); \\ anca.dinischiotu@bio.unibuc.ro (A.D.) \\ 2 Department of Anatomy, Physiology and Biophysics, Faculty of Biology, University of Bucharest, \\ 91-95 Splaiul Independentei, R-050095 Bucharest, Romania; florentina.cojocaru@unibuc.ro \\ 3 Department of General Chemistry, Faculty of Applied Chemistry and Materials Science, Politehnica \\ University of Bucharest, 313 Splaiul Independentei, 060042 Bucharest, Romania; daniela.ionita@upb.ro \\ * Correspondence: madalina.andreea.badea@drd.unibuc.ro \\ + Presented at the 2nd International Online-Conference on Nanomaterials, 15-30 November 2020; Available \\ online: https://iocn2020.sciforum.net/.
}

Citation: Badea, M.A.; Balas, M.;

Cojocaru, F.G.; Ionita, D.;

Dinischiotu, A. Nanoconjugates Based on Cisplatin and SingleWalled Carbon Nanotubes for Therapy of Triple Negative Breast Cancer. Mater. Proc. 2021, 4, 32 . https://doi.org/10.3390/ IOCN2020-07989

Academic Editors: Ana María Díez-Pascual, Antonio Di Bartolomeo and Guanying Chen

\section{Published: 12 November 2020}

Publisher's Note: MDPI stays neutral with regard to jurisdictional

claims in published maps and institutional affiliations.

Copyright: $\odot 2020$ by the authors. Licensee MDPI, Basel, Switzerland. This article is an open access article distributed under the terms and conditions of the Creative Commons Attribution (CC BY) license (http://creativecommons.org/licenses/by/4.0/).

\begin{abstract}
Triple negative breast cancer has a phenotype characterized by the absence of progesterone and estrogen receptors and the lack of HER2 overexpression. In order to find new strategies for treatment, single-walled carbon nanotubes (SWCNT) in combination with chemotherapeutics were studied and tested as new therapeutic tools. The objective of this study was to evaluate the efficiency of SWCNT in the transport of cisplatin (CDDP) for improving its cytotoxic effects on MDA-MB-231 cells. The nanoconjugates SWCNT-COOH-CDDP were obtained by the functionalization of SWCNT with carboxyl groups (SWCNT-COOH) and conjugation with CDDP. MDA-MB-231 cells were exposed to different doses of SWCNT-COOH, SWCNT-COOH-CDDP $(0.01-2 \mu \mathrm{g} / \mathrm{mL})$, and CDDP $(0.00632-1.26 \mu \mathrm{g} / \mathrm{mL})$ for 24 and $48 \mathrm{~h}$. Cellular viability was monitored through an MTT test. The level of reactive oxygen species (ROS) and reduced glutathione (GSH) were evaluated using fluorescence and spectrophotometric methods, respectively. The expressions of Nrf2, caspase-3, caspase- 8 , and Bid proteins were assessed by immunoblotting in the presence of 0.5 and $1 \mu \mathrm{g} / \mathrm{mL}$ nanoconjugates. Additionally, the effects of SWCNT-COOH-CDDP on cell migration were monitored using a wound healing assay. The cellular viability decreased and ROS level increased in a time and dose-dependent manner in the presence of nanoconjugates relative to the control. Moreover, the level of GSH rose after 24 and $48 \mathrm{~h}$ of exposure to $0.5 \mu \mathrm{g} / \mathrm{mL}$ SWCNT-COOH-CDDP, while a decrease to $78.31 \%$ was recorded after $48 \mathrm{~h}$ in the presence of $1 \mu \mathrm{g} / \mathrm{mL}$ nanoconjugates. The expression of Nrf2 decreased to $33 \%$ after $24 \mathrm{~h}$ of treatment with $1 \mu \mathrm{g} / \mathrm{mL}$ SWCNT-COOH-CDDP and increased to $80 \%$ compared to the control (100\%) after $48 \mathrm{~h}$. Upregulation of caspase-3 and caspase8 and downregulation of Bid post-exposure to $1 \mu \mathrm{g} / \mathrm{mL}$ SWCNT-COOH-CDDP was noticed. The inhibition of cell migration was observed after 24 and $48 \mathrm{~h}$ of exposure to $1 \mu \mathrm{g} / \mathrm{mL}$ SWCNT-COOHCDDP. In conclusion, these nanoconjugates induced apoptosis in MDA-MB-231 cells, probably by both intrinsic and extrinsic pathways, by triggering the oxidative stress mechanisms, and inhibited their migration potential.
\end{abstract}

Supplementary Materials: The following are available online at https:/www.mdpi.com/article/ 10.3390/IOCN2020-07989. 